\title{
Etnoconservação e história ambiental para um novo modelo conservacionista do século XXI
}

\section{Etnoconservation and environmental history for a new conservation model of the XXI century}

José Aécio Alves Barbosa - Doutor atuando no Programa de Pós-Graduação em Recursos Naturais da Universidade Federal de Campina Grande. Mestre em Recursos Naturais, Bolsista da CAPES. Membro do Grupo de Trabalho de História Ambiental da Associação Nacional de História e dos Grupos de Pesquisa em Estudos Culturais e em História, Meio Ambiente e Questões Étnicas da UFCG. E-mail: barbosa.joseaecioalves@gmail.com

José Otávio Aguiar - Doutor em História e Ciências Políticas pela UFMG. Possui pósdoutorado em História pela UFPE. Professor associado II da Universidade Federal de Campina Grande. Membro do Grupo de Trabalho de História Ambiental da Associação Nacional de História e coordenador dos Grupos de Pesquisa em Estudos Culturais e em História, Meio Ambiente e Questões Étnicas da UFCG. E-mail: j.otavio.a@gmail.com

\section{Resumo}

Diante do cenário ambiental mundial na atualidade, falar de conservação implica, necessariamente, em abarcar todo o conteúdo que envolve essa temática, a exemplo das questões de cunho socioeconômico, histórico e cultural. Sendo assim, o presente artigo tem como objetivo discutir algumas estratégias que vêm sendo postas como recursos úteis aos novos modelos de conservação necessários ante os desafios do século XXI, expondo a importância da inclusão dessas ferramentas (com destaque à etnoconservação e à história ambiental) na identificação de áreas prioritárias para conservação, e no planejamento, implementação e manutenção de áreas protegidas sustentáveis, usando nessa discussão uma abordagem aberta e interdisciplinar acerca da questão.

\section{Palavras-chave}

Conservação. Meio Ambiente. Sociedade. Cultura.

\begin{abstract}
Against the global environmental scenario today, talk about conservation necessarily imply in encompassing all the content that engages this theme, such as socioeconomic, historical and cultural issues. Thus, this article aims to discuss some strategies that have been placed as useful resources to new conservation models necessary given the challenges of the twenty-first century, exposing the importance of including these tools (especially the etnoconservation and environmental history) to identify priority areas for conservation, and planning, implementing and maintaining sustainable protected areas with a wide and interdisciplinary discussion on the issue.
\end{abstract}

\section{Keywords}

Conservation. Environmental. Society. Culture. 


\section{INTRODUÇÃO}

No Brasil, o obsoleto modelo seguido para delimitação de áreas prioritárias para conservação baseou-se, sobretudo, em padrões adotados pelos parques norte-americanos, onde a natureza deveria permanecer "intocada" e distante da “destrutiva presença humana" (RISSO, 2014).

Em uma ferrenha crítica a esse falido arquétipo, Diegues (2004) chamou-o de "Mito Moderno da Natureza Intocada", o que, convenhamos, foi bastante adequado, uma vez que o modelo mostrava-se absurdamente mítico em se tratando de áreas prioritárias para conservação nos países subdesenvolvidos, na sua maioria, extremamente povoados (AMEND, S.; AMEND, T., 1992).

A adoção desse molde de Unidades de Conservação (UC) gerou como implicação o estabelecimento de diversos "parques" em áreas antes habitadas por comunidades indígenas e tradicionais, desencadeando uma série de conflitos socioambientais decorrentes da ocupação estatal, expropriação e desapropriação dos territórios e sua consequente transformação em áreas protegidas (ARRUDA, 1999; FERREIRA, 2004).

As populações que habitavam essas áreas e seu entorno, antes de sua conversão em "santuários da vida natural", em absolutamente nada participavam das tomadas de decisão, uma vez que se pressupunha uma conflituosa dicotomia humano x natureza (RISSO, 2014). Insatisfeitos, esses habitantes viam agravadas suas condições de vida e, muitas vezes, acabavam por promover maior degradação ambiental que a existente antes da criação da UC, como exemplifica Botkin (1990), ao expor o caso do Tsavo National Park, no leste da África, e Diegues (1996) ao tratar do caso da Ilha do Cardoso, no Brasil; ambos casos em que a retirada das populções nativas locais culminou em maior perdas socioculturais e declínio ecológico.

Nesse contexto, o número de áreas de conservação onde os objetivos conservacionistas não eram atingidos apenas crescia, ao passo que os habitantes locais tinham criminalizados muitos dos seus atos (alguns deles tradicionalmente perpetuados), sendo proibidos de utilizar os recursos naturais e garantir sua manutenção socioeconômica e preservação da identidade cultural (CALEGARE; HIGUSHI; SIQUEIRA, 2008).

O quadro no Brasil começou paulatinamente a ser amenizado com a implementação de UC de Uso Sustentável, a exemplo de Áreas de Proteção Ambiental e Reservas Extrativistas. A adoção, mesmo que imperfeita desse tipo de modelo, de acordo com Sachs (2004), passou a impetrar, além do mapeamento e conservação do ambiente natural, a compreensão dos modos de 
vida e das relações socio-históricas e culturais das populações que habitavam as áreas agora protegidas.

Esse vem sendo um importante passo para o avanço conservacionista no país, uma vez que é inconcebível traçar estratégias de conservação para os recursos naturais sem considerar o elemento humano e sua influência cultural, ambiental e histórica sobre o ambiente (DIEGUES, 2000), considerando que o próprio meio físico e seu ordenamento estão arraigados a significados e interpretações sociais erigidas e repassadas entre as gerações por meio da tradição oral, que acabam por culminar em hábitos e costumes sociais, conhecimento e uso dos recursos ambientais (CALEGARE; HIGUSHI; SIQUEIRA, 2008).

É nesse cenário que a etnoconservação e a história ambiental inseremse como ferramentas eficazes para o levantamento de informações relevantes à adoção de estratégias diligentes de estabelecimento de áreas prioritárias para conservação que considerem os aspectos de ocupação e uso da área, formas de interação com os recursos naturais, percepção ambiental, conflitos de interesses e diversas outras demandas relacionadas. Sendo assim, o presente trabalho visa expor a importância da inclusão dessas ferramentas no plano de estabelecimento de áreas protegidas sustentáveis, em uma abordagem ampla e interdisciplinar sobre o tema.

\section{ETNOCONSERVAÇÃO COMO FERRAMENTA ANTE O MODELO SOCIOAMBIENTAL DO SÉCULO XXI}

As sociedades atuais deparam-se com a ampla questão da complexidade ambiental em virtude de um arcaico modelo de uso insustentável de recursos naturais. Para Leff (2005a), a própria necessidade de recorrer ao termo "sustentabilidade" é o significado de uma falha fundamental na história da humanidade; uma "crise de civilização" que alcança seu momento culminante na modernidade, cujas origens, entretanto, remetem à concepção do mundo que serve de base à civilização ocidental. Além da vulnerabilidade das espécies, o que por si só ameaça o equilíbrio dos mais diversos ecossistemas, impactos de natureza social, econômica, cultural e ambiental têm sistematicamente ocorrido com efeitos desastrosos à vida das populações que dependem diretamente dos recursos naturais para a sua reprodução social (SANTILLI, 2005). Essa gama de questões insurgidas ao longo dos dois últimos séculos veio interrogar o papel dominante da ciência como sintetizadora e direcionadora dos conhecimentos da humanidade (BARBOSA, 2013). 
A crise ambiental, que tomou dimensões marcantes a partir da segunda metade do século XX, transcende a superexploração dos recursos naturais. O cartesianismo da ciência dita moderna subjugou conhecimentos e saberes diversos e suscitou, no cerne de nossa sociedade, a ideia de única verdade como sendo aquela metodologicamente testada ou testável, mediante parâmetros préestabelecidos que, apenas depois de repetidos testes e produção de resultados seriam concretizados (CHEN, 2004). A existência das chamadas "Etnociências" e o estabelecimento de relações possíveis entre elas e as "Ciências" permaneceu para além dos limites do pensável, durante muito tempo (DIAS; JANEIRA, 2005). Assim, era impensável existir a possibilidade de juntar o prefixo éthos a scientiae; também não se podia conceber que pudessem existir outras realidades, com o mesmo radical, fora das ciências modernas (DIAS; JANEIRA, 2005). Ciência e técnica tiveram sua importância relacionada, principalmente a expansão do capitalismo nos séculos XVIII e XIX e no pós-Segunda Guerra Mundial. Neste âmbito, Gonçalves (2004) destaca que:

[...] A ciência e técnica modernas, tal como concebidas pelo Ocidente Europeu e como se expandiram para o mundo, foram instituídas como critério de verdade, como se essa verdade tivesse uma bondade moral naturalmente nela inscrita. Com isso, a verdade científica deslocou outras formas de construção de conhecimento e se tornou uma verdade possuída por uma espécie de mais-valia simbólica: “o que é científico é bom” e, assim, o Estado e os gestores passaram a invocar a verdade científica como se fosse A Verdade. Com isso, outros saberes se tornaram saberes menores - folclore. $O$ saber popular tornou-se um não-saber; a religião perdeu seu reino; a arte passou a ser acessória, entretenimento; a filosofia, pouco a pouco, foi deslocada, e até mesmo a política, para os gregos a mais sublime das artes, passou a ser substituída por uma espécie de saber competente [...] (GONÇALVES. 2004, p. 174. Grifos nossos).

Quaisquer hipóteses ou interpretações de fatos que não se encaixassem com as ideias vigentes da ciência "moderna" seriam ignoradas; quaisquer ensaios de incluir esclarecimentos criados fora do rigor científico ocidental, que fugissem da objetividade, eram banidos dos centros acadêmicos. Contudo, no apogeu desta crise, os demais saberes "não científicos", outrora subjugados, agora passariam a ganhar destaque, como atesta Leff (2005b).

O capitalismo em sua liberalidade, mas, ainda imperialista no início do século XX se caracterizava pela busca por uma produção de bens cada vez maior, e a incompetência em perceber o ambiente como uma fonte de recursos limitados, conduziu a humanidade para a crise ambiental atual. Entretanto, o período Pós-Segunda Guerra Mundial, sobretudo no final da década de 1950 
e início da década de 1960, marca o despertar de uma consciência ambiental (LEFF, 2005a; 2005b).

A partir da percepção da crise ecológica e ambiental, um conceito de ambiente com uma nova visão do desenvolvimento humano foi sendo configurado. Esse conceito reintegraria os valores e potenciais da natureza, as nuances e peculiaridades sociais, os conhecimentos e saberes reprimidos e subjugados, e a complexidade do mundo, renegados pela racionalidade mecanicista, unidimensional, simplificadora e fragmentadora, que regeu o processo de modernização (LEFF, 2005b).

Neste contexto de meados do século XX, ocorre a popularização das etnociências, como uma manifesta oposição ao racionalismo científico dominante. Muitas pesquisas passaram a empregar explicitamente termos precedidos pelo prefixo "etno", do grego Ethnos (identidade de origem/ costume), com variante latina em Ethos (jeito de ser / habitus). Esse prefixo, aplicado à ciência e apresentado em 1964 por Sturtvant, passou a designar as áreas do saber interdisciplinar de documentação, valorização e estudo das práticas e conhecimentos gerados e transmitidos por um grupo cultural (STURTEVANT, 1964).

Para Marques (2002), o que hoje se nomeia como etnociência, já insurgiu no cenário científico, não como um conjugado de disciplinas, todavia, como um campo interdisciplinar, de cruzamento de saberes, que originavam novos campos. Estes saberes foram originários do diálogo entre as ciências naturais e as ciências humanas e sociais. É nesta linha de raciocínio que as etnociências passam a destacar-se, não mais como uma disputa entre cientistas humanos, sociais e naturais, porém, como um pensamento que transcende as fronteiras disciplinares, caminhando em direção a uma almejada interdisciplinaridade (MOURA, 2002).

Os aspectos inerentes à abordagem etnocientífica foram - e vêm sendo - construídos alicerçados ao pressuposto do construtivismo social e abordam especificamente as características culturais de formação e uso de formas de conhecimento. Essa abordagem permite um entendimento de como os humanos variam seus conhecimentos e crenças dentro de contextos histórico-sociais, econômicos, culturais e ecológicos diferentes, a fim de expressar as múltiplas possibilidades apresentadas pelas civilizações humanas (RIST; DAHDOUHGUEBAS, 2006).

Como muitos desses conhecimentos e práticas manifestavam relação direta com o usufruto dos recursos ambientais, inexoravelmente as ciências conservacionistas, apropriando-se e ampliando adequadamente o termo, cunharam a expressão "Etnoconservação", relacionando-a ao cruzamento entre saberes tradicionais e científicos sobre o meio ambiente, de modo a valorizar 
articulações, comparações, conexões, integrações e, quem sabe, aprendizagens multilaterais (MARQUES, 2002; ALVES, 2008).

Em meio às múltiplas subclasses etnocientíficas, a etnoconservação faz jus a uma atenção peculiar por abarcar a análise e classificação de sistemas sobre a natureza e por apresentar uma intensa ligação com os temas da botânica, zoologia e ecologia (MOURÃO; ARAÚJO; ALMEIDA, 2006).

Mesmo sem uma definição universal de etnoconservação, pode-se ter por exemplar a que a expõe como: "o estudo do papel da natureza no sistema de crenças e de adaptação do homem a determinados ambientes, enfatizando as categorias e conceitos cognitivos utilizados pelos povos em estudo, aproveitandose dos paradigmas e da epistemologia da ciência moderna e provendo um arcabouço teórico para interligar diferentes áreas das ciências sociais e naturais com outros sistemas de conhecimentos não acadêmicos, buscando entender os processos de interação das populações humanas com os recursos naturais, com especial atenção à percepção, conhecimento e usos, incluindo o manejo de recursos, contribuindo para esclarecer diferenças sociais e analisar a diversidade ou heterogeneidade cultural" (POSEY, 1986; BEGOSSI; HANAZAKI; SILVANO, 2002; SANTOS-FITA; COSTA-NETO, 2007).

Nesse sentido, as etnociências - com destaque aqui à etnoconservação surgem e firmam-se como novas modalidades científicas agregadoras, que unem áreas específicas do conhecimento a fim de compreender fenômenos que seriam incompreensíveis com os conhecimentos de apenas uma área (BARBOSA, 2011). Essa interação inerente às etnociências é, de fato, essencial para o desenvolvimento científico de caráter interdisciplinar, adequado às necessidades que se colocam frente aos desafios ambientais, sociais e econômicos do século XXI, bem como ao desenvolvimento e manutenção de estratégias que, de fato, mantenham funcionais os eventuais espaços conservacionistas estabelecidos em zonas já habitadas por populações humanas, que teriam sua participação considerada nesse empreendimento, deixando o patamar de meros expectadores de sua exclusão.

Ante o cenário, um dos maiores desafios atuais para a etnoconservação reside exatamente em gerar um embasamento de dados e metodologias seguras ao empreendimento e gestão de UC de Uso Sustentável, com aporte de novos modelos conservacionistas que sejam densos tanto em conhecimento científico, quanto em saberes tradicionais (DIEGUES, 2000), para que, de fato, possam ser aplicados ao gerenciamento e manejo ambiental (LOUREIRO; CUNHA, 2008). Pra isso, contudo, é necessária a gradual abertura tanto da comunidade científica, com a mudança dos velhos paradigmas cartesianos reducionistas que 
definem a ciência clássica como a única detentora do verdadeiro saber sobre o mundo; quanto das populações locais, com a inclusão paulatina dos aspectos histórico-culturais e socioeconômicos dessas populações em análises ambientais (BARBOSA, 2011).

Outro desafio, e esse ainda mais complexo, diz respeito a conseguir-se gerir, de forma realmente sustentável - ambientalmente equilibrada, socialmente justa, econômicamente viável, culturalmente respeitosa e politicamente empenhada - esse modelo de Unidade de Conservação, uma vez que ele exige, para sustentabilidade da gestão, a exposição desnuda e austera de nuances múltiplas das relações humano/natureza, a exemplo dos indicadores sociais e das condições econômicas da população, além de certas peculiaridades culturais e políticas como origem ou agravante das problemáticas ambientais (BARBOSA et al., 2013), considerando a máxima de que "problemas ambientais, em sua grande maioria, são decorrentes de desvios de ordem social e/ ou econômica". $O$ porquê de se considerar esse desafio ainda mais intricado que o primeiro se dá em virtide do cenário sociopolítico comum a países em desenvolvimento, onde essa necessária transparência é um entrave intransponível se considerado que o Estado por vezes tem o hábito mascarar ou transferir as responsabilidades pela origem e agravo dos problemas nacionais, sejam eles ambientais, sociais ou econômicos.

\section{HISTÓRIA AMBIENTAL: NATUREZA, SOCIEDADE, TRADIÇÃO ORAL E OS DESAFIOS DO PRESENTE}

O grande desafio ambiental vivenciado atualmente explicita o quão necessário é assumir uma nova postura investigativa em estudos conservacionistas (CIPRIANO; MACHADO, 2009). Nesse sentido, destaca-se a história ambiental, quando esta, como ciência de campo eminentemente interdisciplinar, historiograficamente dá conta da exploração dos homens e dos recursos naturais no passado e no presente, assim como dos efeitos produzidos, no mundo natural, pelas diversas formações sociais e econômicas (MARTINEZ, 2006).

Na concepção de Leff (2005a), a história - "como uma das mais atrasadas entre as ciências sociais" - esqueceu-se durante muito tempo que seus fatos são condicionados pelo ambiente natural, negligenciando a destruição da natureza por preocupar-se demasiadamente com a dita supremacia humana. Nesse sentido, foi extremamente necessário e relevante à incorporação de variáveis ambientais nos estudos históricos bem como a inserção da história nos estudos da natureza (DRUMMOND, 1991; LEFF, 2005a). Desse modo chega-se à história ambiental, 
que capacita o pesquisador a descobrir a natureza enquanto agente de construção da história, considerando que outras forças significativas atuam sobre o tempo (WORSTER, 1991).

Diante da crise ambiental vivenciada pela humanidade, já apresentada no tópico anterior, bem como frente à urgência em reformular concepções e práticas ambientais segundo o que se entende por sustentável, a história ambiental, aparentemente surgida de motivações morais e compromissos político-éticos, apresenta-se extremamente relevante como campo do conhecimento humano e, à medida que amadurece, transfigura-se em empreendimento acadêmico deveras complexo e indispensável (CIPRIANO; MACHADO, 2009).

A história ambiental constitui-se então, de modo semelhante à etnoconservação, de uma nova forma de análise entre as relações do homem com a natureza, considerando o meio ambiente como agente e presente na história da humanidade, permitindo uma análise mais geral, por vincular fenômenos ambientais a fatores condicionantes da história, sobrepujando fronteiras temporais (FREITAS, 2006; PÁDUA, 2010).

Segundo Worster (1991), o objetivo inicial da história ambiental consiste em aprofundar a compreensão relativa aos impactos que os humanos sofrem em seu ambiente natural e vice-versa. Essa modalidade de prática historiográfica, para Martinez (2006), destaca-se pelo uso das relações sociais e, a partir das mesmas, o uso das relações estabelecidas com a natureza como agentes de construção histórica.

A história ambiental refuta a ideia segundo a qual a vivência das sociedades humanas se deu sem barreiras de cunho natural, destacando que os homens não advêm de um grupo especialmente elegido para dominar a Terra (CIPRIANO; MACHADO, 2009). Desse modo, consequências de feitos ecológicos passados não podem se ignorados na atualidade. Eis a necessidade de fazer emergir visões que permitam repensar e superar as tradicionais formas dominantes de intervenção na natureza (LEFF, 2005a), o que leva mais uma vez ao imperativo de um novo modelo de gestão e manejo dos recursos naturais.

Essa nova vertente histórica, como já mencionado, consiste, sobretudo na tentativa de "colocar a sociedade na natureza" (MUNARI, 2009). Com isso, busca-se equilibrar a interação entre sociedade e meio ambiente (DRUMMOND, 1991), com o suporte de muitas outras disciplinas, uma vez que, em meio à interdependência global, a cooperação interdisciplinar faz-se necessária aos pesquisadores, às disciplinas, bem como ao nosso mundo (WORSTER, 1991).

Como ao longo da história a tradição oral foi a grande responsável pelo repasse de conhecimento tradicional acerca do ambiente, e esse conhecimento, 
por sua vez, modelou as percepções desenvolvidas acerca do meio natural, nada mais coerente que utilizar como metodologia eficaz a história ambiental e a etnoconservação e o próprio discurso - a oralidade (MONTENEGRO, 2007; 2010; MEIHY; RIBEIRO, 2011), uma vez que ela é capaz de detectar a pluralidade de paradigmas envolvidos na questão socioambiental, bem como a existência de contradições internas nas próprias formas pelas quais os atores consultados descrevem a si mesmos, seus projetos, suas concepções e suas atuações sobre o meio (BARBOSA, 2013).

Este tipo de abordagem metodológica, adquirida dos campos críticoteóricos de procedimento em história oral, precisa romper com certos discursos disciplinares somente calcados na ideia de coerência e harmonia entre os sujeitos e os sistemas estudados. Isso porque o processo histórico envolvido nas relações natureza/sociedade/cultura - que precisam ser detalhadamente expostos e considerados de acordo com o novo modelo sustentável de gestão ambiental e estabelecimento de áreas prioritárias para conservação que se pretende alcançar, e sobre o qual o presente trabalho trata desde seu título - é caracterizado por continuidades, mas também, por rupturas tanto em sentido temporal, quanto envolvendo percepções, anseios, necessidades e diversas outras formas de relação e interação entre os atores sociais e o ambiente, que são determinantes para identificação de conflitos e potencialidades, fundamentais para implementar, administrar e manter Unidades de Conservação realmente sustentáveis (MENARIN, 2009).

\section{CONCLUSÃO}

Fica claro que tratar de conservação em cenários onde a problemática ambiental se entrelaça a questões econômicas, sociais, culturais e políticas, a exemplo do que acontece em países em desenvolvimento como o Brasil, exige uma abordagem diferenciada e abrangente que considere ao máximo essa multiplicidade de fatores.

Nesse percurso, a abordagem etnoconservacionista tem se mostrado bastante eficaz, por conseguir se postar de forma interdisciplinar, considerando a amplitude dos conhecimentos, relações e interações estabelecidas entre os seres humanos e o ambiente que os cerca.

Como essa relação humano/natureza é instituída desde os primórdios da civilização, sua análise exige um recorte temporal mais amplo, uma vez que atuais circustâncias socioambientais podem ter origem em eventos do passado. Desse modo, a história ambiental amplifica as possibilidades de compreensão do 
ambiente e de como ele e seus atores foram se articulando ao longo do tempo na construção de um cenário atual.

Assim posto, uma política conservacionista eficiente e que responda às múltiplas necessidades envolvidas, precisa portar-se de forma a considerar, além da dinâmica ambiental, o contexto das pessoas inseridas em seu entorno, tanto no presente quanto no passado, para só assim, ter perspectiva de futuro.

\section{REFERÊNCIAS}

ALVES, Â. G. C. Pesquisando pesquisadores: aspectos epistemológicos na pesquisa etnoecológica. In: REUNIÃO ANUAL DA SOCIEDADE BRASILEIRA PARA O PROGRESSO DA CIÊNCIA, 60. Associação Brasileira de Antropologia. Campinas-SP, 2008. Anais... Campinas: Unicamp, 2008.

AMEND, S.; AMEND, T (Coord.). Espacios sin habitantes? Parques nacionales de America del Sur. Caracas: Editorial Nueva Sociedad/IUCN, 1992.

ARRUDA, R. "Populações tradicionais" e a proteção dos recursos naturais em unidades de conservação. Ambiente \& Sociedade, São Paulo, v. 2, n. 5, p. 79 92, 1999.

BARBOSA, J. A. A. A caça e o uso da fauna no Agreste: um estudo etnobiológico a partir da memória dos caçadores do município de Queimadas-PB (1940-2012). 2013. 136f. Dissertação (Mestrado em Recursos Naturais) - Universidade Federal de Campina Grande, Campina Grande-PB, 2013.

Interdisciplinaridade, educação e sociedades - Breves considerações críticas. Rev. Âmbito Jurídico, Rio Grande-RS, v. 14, n. 91, p. 1-8, 2011.

BARBOSA, J. A. A.; ALMEIDA, A. L. L.; SILVA, G. L. A.; MARQUES, L. S.; SANTOS, L. F. F.; RAMALHO, M. S.; DÔSO, M. F.; NOGUEIRA, R. L.; ALMEIDA, S. K. A. Breves considerações críticas sobre a sustentabilidade no cenário socioeconômico e comportamental na atualidade. Rev. Âmbito Jurídico, Rio Grande-RS, v. 16, n. 119, p. 1-8, 2013.

BEGOSSI, A; HANAZAKI, N.; SILVANO, R. A. M. Ecologia Humana, Etnoecologia e Conservação. In: AMOROZO, M. C. M.; MING, L. C.; SILVA, S. M. P. (Ed.). Métodos de coleta e análise de dados em Etnobiologia e disciplinas correlatas. Rio Claro, SP: UNESP/CNPq, 2002. p. 93-128

BOTKIN, D. B. Discordant harmonies: a new ecology for the twenty-first century. New York: Oxford University Press, 1990. 
CALEGARE, M. G. A.; HIGUCHI, M. I. G.; SIQUEIRA, M. S. Indicadores socioambientais do modo de vida de populações tradicionais em Unidade de Conservação. In: ENCONTRO DA REGIÃO NORTE DA SOCIEDADE BRASILEIRA DE SOCIOLOGIA, 3.: Amazônia e Sociologia: fronteiras do século XXI. GT 13- Sociedade e ambiente: redes de sociabilidade e relações com a natureza no Norte e Sudeste do Brasil. Manaus, 2008. Anais... Manaus, 2008

CHEN, X. Culture and understanding: the Cartesian suspicion, the Gadamerian response, and the Confucian outcome. Journal of Chinese Philosophy, v. 31, n. 3, p. 389-403, 2004.

CIPRIANO, D. M.; MACHADO, C. R. S. Algumas reflexões sobre o estudo da história Oral da/na cidade. Relatório de Pesquisa. Universidade Federal do Rio Grande e Conselho Nacional de Desenvolvimento Científico e Tecnológico. 2009.

DIAS, A. S.; JANEIRA, A. L. Entre ciência e etnociências. Episteme, Porto Alegre, n. 21, p. 107-127, 2005.

DIEGUES, A. C. O mito moderno da natureza intocada. São Paulo: Hucitec, 2004.

(Org.) Etnoconservação: novos rumos para a proteção da natureza nos trópicos. 2. ed. São Paulo, NUPAUB-USP, 2000.

Repensando e recriando as formas de apropriação comum dos espaços e recursos naturais. In: VIEIRA, P. F.; WEBER, J. (Org.) Gestão de recursos naturais renováveis e desenvolvimento. São Paulo, Cortez Editora, 1996.

DRUMMOND, J. A história ambiental: temas, fontes e linhas de pesquisa. Estudos Históricos, Rio de Janeiro, v. 4, n. 8, p. 177-197, 1991.

FERREIRA, L. C. Dimensões humanas da biodiversidade: mudanças sociais e conflitos em torno de áreas protegidas no Valo do Ribeira, SP, Brasil. Ambiente \& Sociedade, São Paulo, v. 7, n. 1, p. 47-68, 2004.

FREITAS, I. História Ambiental e Geografia. In: ENCONTRO REGIONAL DE HISTÓRIA DA ANPUH, 12. Anais... 2006.

GONÇALVES, C. W. P. O desafio ambiental. Rio de Janeiro: Record, 2004. p. 179.

LEFF, H. Saber ambiental. 4. ed. Petrópolis-RJ: Vozes, 2005a. 494 p. 
Construindo a história ambiental da América Latina. Esboços / UFSC. n. 13, p.11-26, 2005b.

LOUREIRO; C. F. B.; CUNHA, C. C. Educação ambiental e gestão participativa de Unidades de Conservação: elementos para se pensar a sustentabilidade democrática. Ambiente \& Sociedade, São Paulo, v. 11, n. 2, p. 237-253, 2008.

MARQUES, J. G. W. O olhar (des)multiplicado. O papel do interdisciplinar e do qualitativo na pesquisa etnobiológica e etnoecológica. In: AMOROZO, M. C. M.; MINGG, L. C.; SILVA, S. M. P. (Ed.). Métodos de coleta e análise de dados em etnobiologia, etnoecologia e disciplinas correlatas. Rio Claro-SP: UNESP/CNPq, 2002. p. 31-46.

MARTINEZ, P. H. História Ambiental no Brasil: pesquisa e ensino. São Paulo: Cortez, 2006.

MEIHY, J. C. S. B.; RIBEIRO, S. L. S. Guia prático de História Oral. São Paulo: Loyola, 2011.

MENARIN, C. A. Unidades de Conservação: abordagens e características geográficas. Patrimônio e Memória, São Paulo, v. 5, n. 1, p. 195-201, 2009.

MONTENEGRO, A. T. História, metodologia, memória. São Paulo: Contexto, 2010.

História Oral e memória: a cultura popular revisitada. 6. ed. São Paulo: Contexto, 2007.

MOURA, F. P. Entre o peixe e o dendê: etnoecologia do povo dos Marimbús (Chapada Diamantina-BA). 2002. 121f. Tese (Doutorado em Ecologia e Recursos Naturais) - Universidade Federal de São Carlos, São Carlos-SP, 2002.

MOURÃO, J. S.; ARAUJO, H. F. P.; ALMEIDA, F. S. Ethnotaxonomy of mastofauna as practised by hunters of the municipality of Paulista, state of Paraíba-Brazil. Journal of Ethnobiology and Ethnomedicine, v. 2, n. 19, p. 7, 2006.

MUNARI, L. C. Memória social e ecologia histórica: a agricultura de coivara das populações quilombolas do Vale do Ribeira e sua relação com a formação da Mata Atlântica local. 2009. 217f. Dissertação (Dissertação de Mestrado) Instituto de Biociências, Universidade de São Paulo, São Paulo, 2009.

PÁDUA, J. A. As bases teóricas da história ambiental. Estudos Avançados, São Paulo, v. 24, n. 68, p. 81-101, 2010. 
POSEY, D. Introdução a Etnobiologia: teoria e prática. Suma Etnológica Brasileira, Petrópolis-RJ, v. 1, n. 1, p. 15-25, 1986.

RISSO, L. C. Unidades de conservação e comunidades: espaços de participação e conflitos territoriais. In: CONGRESSO IBEROAMERICANO DE ESTUDIOS TERRITORIALES Y AMBIENTALES, 6. São Paulo, 2014. Anais... São Paulo: UNESP, 2014.

RIST, S.; DAHDOUH-GUEBAS, F. Ethnosciences - A step towards the integration of scientific and indigenous forms of knowledge in the management of natural resources for the future. Environ Dev Sustain, v. 8, p. 467-493, 2006.

SACHS, I. Desenvolvimento includente, sustentável, sustentado. Rio de Janeiro: Garamond, 2004.

SANTILLI, J. Socioambientalismo e novos direitos. São Paulo: Peirópolis, 2005.

SANTOS-FITA, D.; COSTA-NETO, E. M. As interações entre os seres humanos e os animais: a contribuição da etnozoologia. Biotemas, Florianópolis, v. 20, n. 4, p. 99-110, 2007.

STURTEVANT, W. C. Studies in Ethnoscience. American Anthropologist, v. 66, n. 3 Part 2: Transcultural Studies in Cognition, p. 99-131, 1964.

WORSTER, D. Para fazer história ambiental. Estudos Históricos, Rio de Janeiro, v. 4, n. 8, p. 198-215, 1991. 
